\title{
Bisphenol A removal by a membrane bioreactor
}

\author{
Jianhua Chen $^{\text {a }}$, Xia Huang ${ }^{\mathrm{a}, *}$, Duujong Lee ${ }^{\mathrm{b}}$ \\ ${ }^{a}$ Environment Simulation and Pollution Control State Key Joint Laboratory, Department of Environmental Science and Engineering, \\ Tsinghua University, Beijing 100084, China \\ ${ }^{\mathrm{b}}$ Chemical Engineering Department, National Taiwan University, Taipei 10617, Taiwan \\ Received 8 May 2007; received in revised form 3 January 2008; accepted 6 January 2008
}

\begin{abstract}
Endocrine disrupting chemicals (EDCs) are potentially harmful chemicals during wastewater reclamation. Bisphenol A (BPA) is a typical EDC, and its removal using a submerged membrane bioreactor (MBR) was investigated. For comparison, a conventional activated sludge reactor (CASR) was simultaneously tested using the same BPA sludge loadings as the MBR. The results showed that MBR could remove BPA a little more effectively than CASR, despite changes in sludge loadings ranging from 0.046 to $10.2 \mathrm{~g} \mathrm{~kg}^{-1} \mathrm{~d}^{-1}$. However, MBR could bear much higher volume loadings than CASR and still achieve the same BPA removal efficiencies. In MBR, HRT did not obviously influence the removal of BPA. The results also showed that the contributions of sludge adsorption to BPA removal were quite low in both reactors. In addition, one metabolite of BPA biodegradation, 4-hydroxy-acetophenone, was detected. These results suggested that biodegradation dominated the BPA removal process.
\end{abstract}

(C) 2008 Elsevier Ltd. All rights reserved.

Keywords: BPA; Membrane bioreactor; Removal; Adsorption; Biodegradation

\section{Introduction}

Wastewater reclamation has been attracting attention as a potential countermeasure for alleviating water shortage problems. To ensure the safety of reclaimed water, enhanced treatment for toxic trace chemical pollutants, such as endocrine disrupting chemicals (EDCs), is required. The membrane bioreactor (MBR) is an effective wastewater treatment process developed in recent decades, and is a potential technique for wastewater reclamation. Although the effluent quality of MBR is generally better than that of conventional treatment processes, it is unknown whether it is effective enough to remove EDCs. Thus, it is necessary to investigate the performance of the MBR in removal of EDCs.

Bisphenol A (BPA) is a typical EDC. It is used to synthesize polycarbonates and epoxy resins, flame retardants, and other specialty products $[1,2]$. Because of its wide use, BPA has been detected in many places in the world. The maximum concentrations of BPA detected were $17.2 \mathrm{mg}^{-1}$ in waste landfill leachates [3]. In China, the investigation in a typical municipal wastewater treatment plant found that there was

\footnotetext{
* Corresponding author. Tel.: +8610 62772324; fax: +86 1062771472. E-mail address: xhuang@tsinghua.edu.cn (X. Huang).
}

$825 \mu \mathrm{g} \mathrm{l}^{-1}$ BPA in influent [4]. BPA was also adsorbed by the activated sludge, within a concentration range of 0.033 $36.7 \mu \mathrm{g} \mathrm{g}^{-1}$ in Canada [5], 30-330 $\mu \mathrm{g} \mathrm{g}^{-1}$ in Germany [6] and $28.3 \mu \mathrm{g} \mathrm{g}^{-1}$ in China [7]. The potential risks of BPA included reproduction and development effects, neurochemical effects and behavioral effects [8]. However, the low dose effect should not be neglected $[9,10]$. Some enhanced removal methods for BPA have been investigated [11-17], and the BPA-degradable bacteria have been isolated from activated sludge [18] and river water [19]. The degradation pathway has also been studied [20].

Some studies have shown that MBRs could remove more than $80 \%$ of nonylphenol and BPA from dumpsite leachate [21,22]. Other researchers found that both MBR and conventional activated sludge plants could remove some pharmaceutical substances [23]. All of these studies indicated that the MBR had the potential to remove EDCs, but the fate of EDCs in the treatment process was not yet clear. Moreover, because of the hydrophobicity of many EDCs, the excess sludge would also be a potential source of risks.

Thus, this study focused on BPA removal in a submerged MBR without active sludge discharge in order to reduce the secondary pollution. A conventional activated sludge reactor (CASR) was simultaneously tested, and the removal efficiencies of BPA at different BPA sludge loadings were compared. In addition, the contributions of adsorption and biodegradation to 
BPA removal were investigated. Preliminary investigation of BPA metabolites was also conducted to better understand the biodegradation behavior of BPA in MBR.

\section{Materials and methods}

\subsection{Experimental equipment and operational conditions}

A submerged membrane bioreactor and a conventional activated sludge reactor were used in the continuous experiments (Fig. 1(a) and (b)).

The volume of MBR was 101 . A polyethylene hollow fiber membrane module (Korea Membrane Separation Co. Ltd., Korea), with an effective area of $0.2 \mathrm{~m}^{2}$ and a nominal pore size of $0.4 \mu \mathrm{m}$, was used in the MBR. The CASR, with a total volume of 24.81 , consisted of an aeration tank (20.4 1) and a settling tank (4.4 1).

Both reactors were seeded with activated sludge taken from Qinghe WWTP of Beijing, China. Before addition of BPA (Sigma-Aldrich, purity $\geq 97 \%$ ), the sludge was first incubated in reactors for 3 weeks with the synthetic influent containing COD of $400 \mathrm{mg} \mathrm{l}^{-1}, \mathrm{NH}_{4}^{+}-\mathrm{N}$ of $35 \mathrm{mg} \mathrm{l}^{-1}$ and TP of $9 \mathrm{mg} \mathrm{l}^{-1}$. Except for some necessary usages and the release with the effluent, sludge was not discharged from either reactor. In the MBR, aeration was applied with an air flow rate of $0.4-0.6 \mathrm{~m}^{3} \mathrm{~h}^{-1}$ to create turbulence for retarding membrane fouling, and the dissolved oxygen (DO) was within the range of 4-6 $\mathrm{mg}^{-1}$. For comparison, the DO in the CASR was controlled to approach the ranges in the MBR.

In the first stage, Run-1 to Run-3, the comparison of the BPA removal between MBR and CASR was conducted using the same BPA sludge loadings. Since the sludge was inactively discharged, the SRT of MBR achieved $350 \mathrm{~d}$, but that of CASR was only $40 \mathrm{~d}$ because of the extra effluent SS. The HRTs of MBR and CASR were 8 and $11 \mathrm{~h}$ respectively, according to the normal state of these two types of processes. Different BPA sludge loadings were achieved by changing the influent concentrations of BPA from 0.1 to $5 \mathrm{mg} \mathrm{l}^{-1}$ and then to $20 \mathrm{mg} 1^{-1}$ corresponding to Run-1, Run-2 and Run-3, respectively. Moreover, in Run-3, the HRT of CASR was prolonged to slow the sludge decrease caused by the increased effluent SS.

In the second stage, Run-4 to Run-6, in order to investigate whether the HRT would influence the BPA removal in MBR, HRTs of MBR were shortened from 8 to $6 \mathrm{~h}$ and then to $4 \mathrm{~h}$, while influent concentrations of BPA were kept constant.

(a)

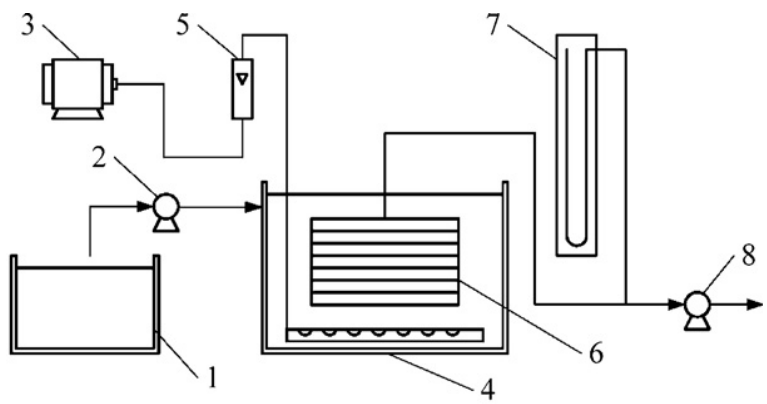

(b)

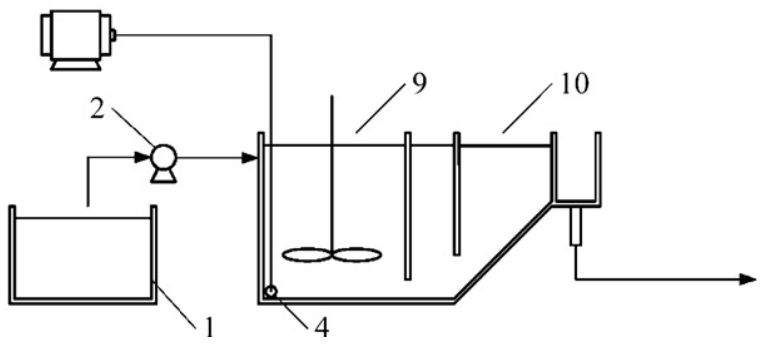

Fig. 1. Diagrams of the submerged MBR (a) and CASR (b). (1) Influent reservoir, (2) influent pump, (3) air compressor, (4) perforated diffuser, (5) air flow meter, (6) membrane module, (7) manometer, (8) suction pump, (9) aeration tank and (10) settling tank.

\subsection{Batch experiments on sludge adsorption of BPA}

Sludge adsorption tests of BPA were performed to study the fate of BPA in MBR and CASR. The adsorption isothermal curve was investigated, and the contribution of adsorption to BPA removal was calculated. The equilibrium time was previously determined to be $30 \mathrm{~min}$.

The different equilibrium concentrations of BPA were achieved by spiking different concentrations of BPA $\left(2.5,5.0,10.0,20.0\right.$, and $\left.40.0 \mathrm{mg}^{-1}\right)$ into the same masses of sludge. The sludge, taken from MBR and CASR before or after BPA addition, was centrifuged at $8000 \mathrm{rpm}$ at $4{ }^{\circ} \mathrm{C}$ for $10 \mathrm{~min}$, and was then softly washed. After adding sodium azide to sterilize the sludge, the mixture was placed in conical flasks and shaken at $150 \mathrm{rpm}$ at $20^{\circ} \mathrm{C}$ for $30 \mathrm{~min}$, and then centrifuged at $8000 \mathrm{rpm}$ at $4{ }^{\circ} \mathrm{C}$ for $5 \mathrm{~min}$. Finally, the supernatant was filtered by a $0.45 \mu \mathrm{m}$ membrane and the BPA concentrations were determined by HPLC. The recoveries were $81.7 \pm 6.8 \%$ to BPA of $2.0 \mathrm{mg}^{-1}, 99.7 \pm 5.7 \%$ to $5.0 \mathrm{mg}^{-1}$ and $99.0 \pm 0.4 \%$ to $20 \mathrm{mg}^{-1}$. The experiments were performed twice for each concentration level. The control samples without sludge were simultaneously processed under the same conditions. The results showed that BPA was steady during the entire process without sludge.

The specific adsorption coefficient $K_{\mathrm{D}}\left(1 \mathrm{~kg}^{-1}\right)$ was calculated as the equation in Ref. [24].

\subsection{Analytical methods}

\subsection{1. $B P A$}

BPA was analyzed by HPLC (hp-1050, USA) with a reverse-phase C-18 column (Aichrombond-AQ C18, $4.6 \mathrm{~mm} \times 250 \mathrm{~mm}, 5 \mu \mathrm{m}$, USA), a mobilephase of water and acetonitrile (30:70), a flow of $1 \mathrm{ml} \mathrm{min}^{-1}$, and a UV detector (hp-1040M, USA) at $278 \mathrm{~nm}$ at room temperature.

An additional solid-phase extraction (SPE) process was conducted for the lower concentration of BPA in Run-1. The SPE cartridge (Superlclean ENVI18 , Supelco, USA) was conditioned with $7.5 \mathrm{ml}$ methanol and $7.5 \mathrm{ml}$ purified water at a flow rate of $1 \mathrm{ml} \mathrm{min}^{-1}$, then the sample was loaded at a rate of $5 \mathrm{ml} /$ min. After being dried through overnight freezing-drying, the cartridge was eluted with $5 \mathrm{ml}$ methanol at a rate of $1 \mathrm{ml} \mathrm{min}^{-1}$. The eluate was dried with nitrogen at $40{ }^{\circ} \mathrm{C}$, and redissolved in $0.5 \mathrm{ml}$ methanol for HPLC analysis. The recovery of SPE was $100.6 \pm 6.9 \%(n=3)$.

\subsubsection{Metabolites of BPA}

To investigate the biodegradation of BPA, $100 \mathrm{ml}$ of BPA $\left(20 \mathrm{mg} \mathrm{l}^{-1}\right)$ was mixed with sludge, then the mixture was centrifuged and the supernatant was obtained for the measurement of BPA metabolites.

After acidification with $1 \mathrm{~mol}^{-1}$ sulphuric acid to $\mathrm{pH} 2.5$, the supernatant was loaded onto a SPE cartridge (Superlclean ENVI-18, Supelco, USA), which was conditioned with $5 \mathrm{ml}$ methanol, $5 \mathrm{ml}$ acetone and $5 \mathrm{ml}$ purified water at a flow rate of $1 \mathrm{ml} \mathrm{min}^{-1}$. Then the cartridge was dried with a soft nitrogen stream and eluted with $10 \mathrm{ml}$ acetone at a rate of $1 \mathrm{ml} \mathrm{min}^{-1}$. The eluate was dried with nitrogen at $40{ }^{\circ} \mathrm{C}$, redissolved in $1 \mathrm{ml}$ acetone, and analyzed by GC-MS. The GC-MS (DSQ, Thermo, USA) was operated in electron impact (EI) and full scan mode, with a DB-5MS capillary column $(30 \mathrm{~m} \times 0.25 \mathrm{~mm}$ i.d., $0.25 \mu \mathrm{m}$ film, J\&W, USA). The carrier gas is helium. The temperature program is from $70{ }^{\circ} \mathrm{C}$ (initial time, $2 \mathrm{~min}$ ) to $300{ }^{\circ} \mathrm{C}$ (hold time, $30 \mathrm{~min}$ ) at a rate of $10{ }^{\circ} \mathrm{C} \mathrm{min}^{-1}$.

\section{Results and discussion}

\subsection{Comparison of BPA removal between MBR and CASR}

In the first stage, comparison of BPA removal between MBR and CASR was conducted based on similar sludge loadings in both reactors.

In Run-1, the effluent concentrations of BPA decreased with time in both reactors. Before the 21st day, the effluent concentrations of MBR were almost all lower than those of CASR, but they tended to remain the same during the following 

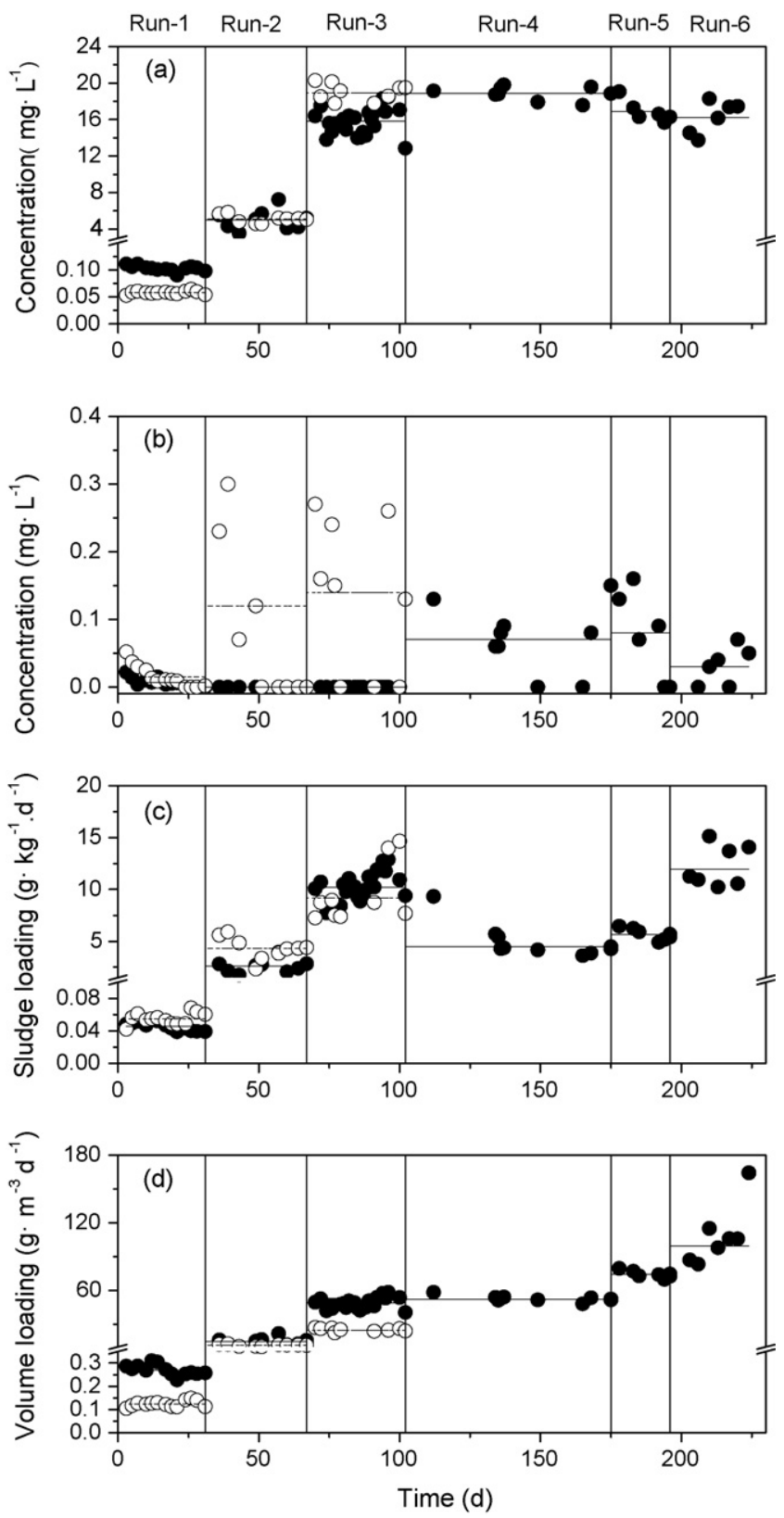

Fig. 2. Comparison of BPA removal between MBR $(\bullet)$ and CASR $(\bigcirc)$ with the average values of MBR (-) and CASR $(\cdots)$. The HRTs were set as $8.0 \pm 0.2 \mathrm{~h}$ for MBR from Run-1 to Run-3, and 8.0, 5.3 and $3.9 \mathrm{~h}$ in Run-4, Run-5 and Run-6, respectively. The HRT was set as $11.0 \pm 0.2 \mathrm{~h}$ for CASR from Run-1 to Run-2, but in Run-3, it was prolonged to $17.9 \mathrm{~h}$ to decrease the sludge release. The SRT was $350 \mathrm{~d}$ in MBR from Run-1 to Run-6, and $40 \mathrm{~d}$ in CASR from Run-1 to Run-3. (a) Influent concentrations of BPA. (b) Effluent concentrations of BPA. (c) BPA sludge loadings. (d) BPA volume loadings.

days (Fig. 2(b)). In Run-2 and Run-3, there were some fluctuations in the BPA concentrations of the influent because of the difficulty in dissolution of BPA. Because the higher concentrations after extraction may harm the HPLC column, the pretreatment of samples was not used in these two run periods. The concentrations of BPA in effluents of MBR were under the minimum limit of HPLC, but those of CASR were in the range of $0.07-0.27 \mathrm{mg} \mathrm{l}^{-1}$ on most sampling days (Fig. 2(b)). These concentrations were all higher than those of MBR. The removal rates of MBR were on average higher than $93.7 \%$, but those of CASR averaged 73.2, 97.8 and $99.3 \%$, respectively.

The sludge loadings of BPA in MBR are also shown in Fig. 2(c). The average sludge loadings of BPA in MBR were $0.046,2.6$ and $10.2 \mathrm{~g} \mathrm{~kg}^{-1} \mathrm{~d}^{-1}$, and those in CASR were 0.055 , 4.3 and $9.2 \mathrm{~g} \mathrm{~kg}^{-1} \mathrm{~d}^{-1}$. The sludge loadings of BPA in both reactors were at approximately equal levels. This showed that both MBR and CASR could effectively remove BPA despite the changes in sludge loadings. The MBR could remove BPA faster than CASR, but as time passed, the efficiencies of these two reactors tended to equalize.

The volume loadings of BPA in MBR were 0.3, 14.7 and $48.8 \mathrm{~g} \mathrm{~m}^{-3} \mathrm{~d}^{-1}$, and those in CASR were $0.1,11.4$ and $24.8 \mathrm{~g} \mathrm{~m}^{-3} \mathrm{~d}^{-1}$, corresponding to Run-1, Run-2 and Run-3, respectively (Fig. 2(d)). This showed that MBR could bear higher BPA volume loadings than CASR to achieve similar removal efficiencies because of its higher MLSS.

After adding BPA in higher concentrations (Run-2 and Run3 ), the removal of BPA by both reactors was easier than expected. The variation of BPA effluent concentrations of MBR could not be shown directly because they were lower than the limitation of the analytical method on almost all of the sampling days, but the effluent concentrations of BPA of CASR showed a similar trend as the lower concentration run (Run-1). This showed that the acclimating procedure of sludge to BPA in MBR required less time than in CASR. This could be caused by the higher diversity of microorganisms in MBR.

To decrease the probable secondary pollution of BPA released from the excess sludge, we took a mode with inactive sludge discharge. The SRT in this mode reflects the characteristics of the reactors, that is, MBR could keep a very long SRT through the membrane rejection of the sludge, but CASR could only achieve a SRT of $40 \mathrm{~d}$ resulted by the effluent SS. According to the Monod kinetic model and experiments, a critical SRT for removal of BPA at $10{ }^{\circ} \mathrm{C}$ of $10 \mathrm{~d}$ was identified by Clara et al. [25]. He states that a complete removal of BPA would be expected with SRTs higher than this value. According to his equation, the critical SRT at $20{ }^{\circ} \mathrm{C}$ was calculated to be $5 \mathrm{~d}$. In our experiments, the SRTs in MBR and CASR were 350 and $40 \mathrm{~d}$, respectively, all much higher than this value. Therefore, the influence of the different SRTs between MBR and CASR should not be obvious.

\subsection{Influence of HRT on BPA removal in $M B R$}

In the second stage, to investigate the influence of HRT on BPA removal in MBR, the influent concentrations of BPA were kept at constant level, and HRTs were shortened from 8.0 to $5.3 \mathrm{~h}$ and then to $3.9 \mathrm{~h}$. The results are shown in Fig. 2. The volumetric loadings of BPA increased from 52.2 to 74.4 , and then gradually to $99.2 \mathrm{~g} \mathrm{~m}^{-3} \mathrm{~d}^{-1}$ (Fig. 2(c)), but the effluent concentrations of BPA were not obviously changed. The results showed that HRT did not obviously influence the BPA removal in MBR.

The BPA sludge loadings were also calculated and plotted in Fig. 2(d), which showed that the sludge loadings were almost in 


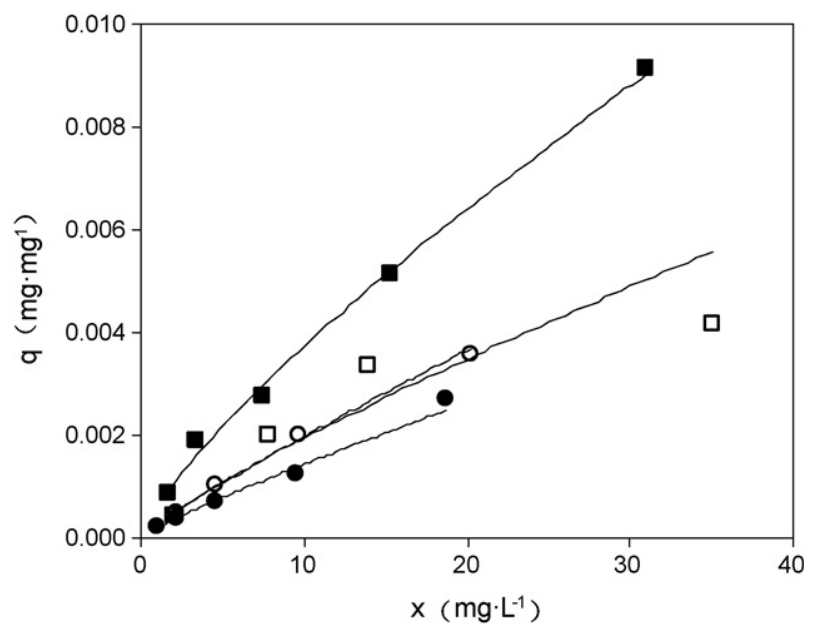

Fig. 3. The adsorption isothermal curves of BPA adsorbed by sludge from MBR before $(\bigcirc)$ and after ( $\bigcirc)$ BPA was added and from CASR before $(\square)$ and after (ם) BPA was added. The $x$ represents the equilibrium concentration of BPA in liquor. The $q$ represents the adsorbed BPA in sludge when in equilibrium. The fitting equations for MBR were $q=0.0003 x^{0.8897}\left(R^{2}=0.9985\right)$ and $q=0.0002 x^{0.8721}\left(R^{2}=0.9947\right)$ before and after BPA was added, respectively. Those for CASR were $q=0.0003 x^{0.8405}\left(R^{2}=0.9221\right)$ and $q=0.0006 x^{0.7810}$ $\left(R^{2}=0.9863\right)$ before and after BPA was added, respectively.

the same ranges as in the first stage. Although the effluent concentrations of BPA were frequently higher than the detection limit of HPLC, they were still lower than those of CASR in the first stage.

\subsection{Contribution of sludge adsorption to BPA removal}

The adsorption isothermal curves are shown in Fig. 3. The fitting results showed that the sludge adsorption of BPA followed the Freundlich adsorption. This could match the experimental results reported by Clara et al. [24]. Before adding BPA into the reactors, the adsorbability of sludge in MBR was almost same as that of CASR. After BPA had been in the reactors for a certain time, the adsorbability changed slightly. However, the range of $\log K_{\mathrm{D}}$ was from 2.00 to 2.75 , which was similar to the reported value between 1.89 and 2.41 [24]. This result suggests that the differences of adsorption isothermal curves between the sludge of MBR and CASR might not be caused by the differences in sludge characteristics, but by the differences between experiments.

The masses of adsorbed BPA were calculated based on the experimental adsorption isothermal equations (Table 1). The results showed that the percentages of adsorbed BPA to total removed BPA were quite low. Therefore, the sludge adsorption did not dominate the BPA removal in both MBR and CASR.

\subsection{The metabolite of BPA biodegradation in $M B R$}

Further investigation of BPA biodegradation was performed by preliminary detection of BPA metabolites. One of the metabolites of BPA biodegradation by bacterium [20], 4hydroxy-acetophenone (Fig. 4(b)), was detected in the sample. It proved that BPA could be biodegraded by bacteria in activated sludge of MBR.

\subsection{Further discussion}

Firstly, BPA losses due to evaporation could be ignored because BPA is low-volatility. The vapor pressure of BPA is $5.3 \mu \mathrm{Pa}$, and the calculated Henry's constant is $10 \mu \mathrm{Pa} \mathrm{m}{ }^{3} \mathrm{~mol}^{-1}$ [2]. Chemicals with Henry's constant lower than $10 \mathrm{mPa} \mathrm{m}^{3} \mathrm{~mol}^{-1}$ are considered low-volatility, as the chemical is less volatile than water [2]. Secondly, as was our initial assumption, the adsorption of BPA should be an important contribution to BPA removal. If such was the case, the effluent concentrations of BPA should increase with the continuous injection of the influent. However, the effluent concentrations of BPA either continuously decreased or stayed below detection limit in experiments. This result suggests that biodegradation occurred. Furthermore, adsorption contributed very little to the removal, according to the calculation of the adsorbed BPA, so biodegradation dominated the removal. What should be emphasized is that sludge adsorption might play an important role in the process of BPA removal. In both activated and inactivated sludge, there was immediate adsorption of BPA in the initial period; subsequently BPA concentration decreased gradually in activated sludge but remained steady in inactivated sludge (data not shown). This suggests that microorganisms might need contact with the BPA through adsorption in order to achieve biodegradation. Similar phenomena were also reported by Urase and Kikuta [26]. Thirdly, the detection of intermediate products of BPA biodegradation could also help demonstrate the importance of biodegradation.

Many studies have reported that there are bacteria capable of degrading BPA [27]. Because of the rejection by membranes, the amount of microorganisms in MBR was higher than that in CASR (Table 1), and the diversity of microorganisms in MBR

The contributions of BPA adsorption to BPA removal in MBR and CASR

\begin{tabular}{|c|c|c|c|c|c|c|c|c|c|}
\hline & \multicolumn{6}{|l|}{ MBR } & \multicolumn{3}{|l|}{ CASR } \\
\hline & Run-1 & Run-2 & Run-3 & Run-4 & Run-5 & Run-6 & Run-1 & Run-2 & Run-3 \\
\hline Concentration of BPA in mixed liquor $\left(\mathrm{mg} \mathrm{l}^{-1}\right)$ & 0.007 & ND & ND & 0.07 & 0.08 & 0.03 & 0.016 & 0.12 & 0.14 \\
\hline $\operatorname{MLSS}\left(\mathrm{mg} \mathrm{l}^{-1}\right)$ & 5200 & 5550 & 5700 & 12,130 & 13,670 & 9060 & 2300 & 3230 & 2800 \\
\hline Mass of adsorbed BPA (mg) & 0.1 & - & - & 2.4 & 3.0 & 0.8 & 1.1 & 7.6 & 7.4 \\
\hline Mass of added BPA $\left(10^{3} \mathrm{mg}\right)$ & 0.07 & 5.1 & 21.9 & 36.1 & 14.5 & 20.7 & 0.0725 & 8.1 & 25.9 \\
\hline Percentage of adsorbed to added (\%) & 0.19 & - & - & 0.01 & 0.02 & 0.004 & 1.35 & 0.09 & 0.03 \\
\hline
\end{tabular}

"ND" means not detected. 

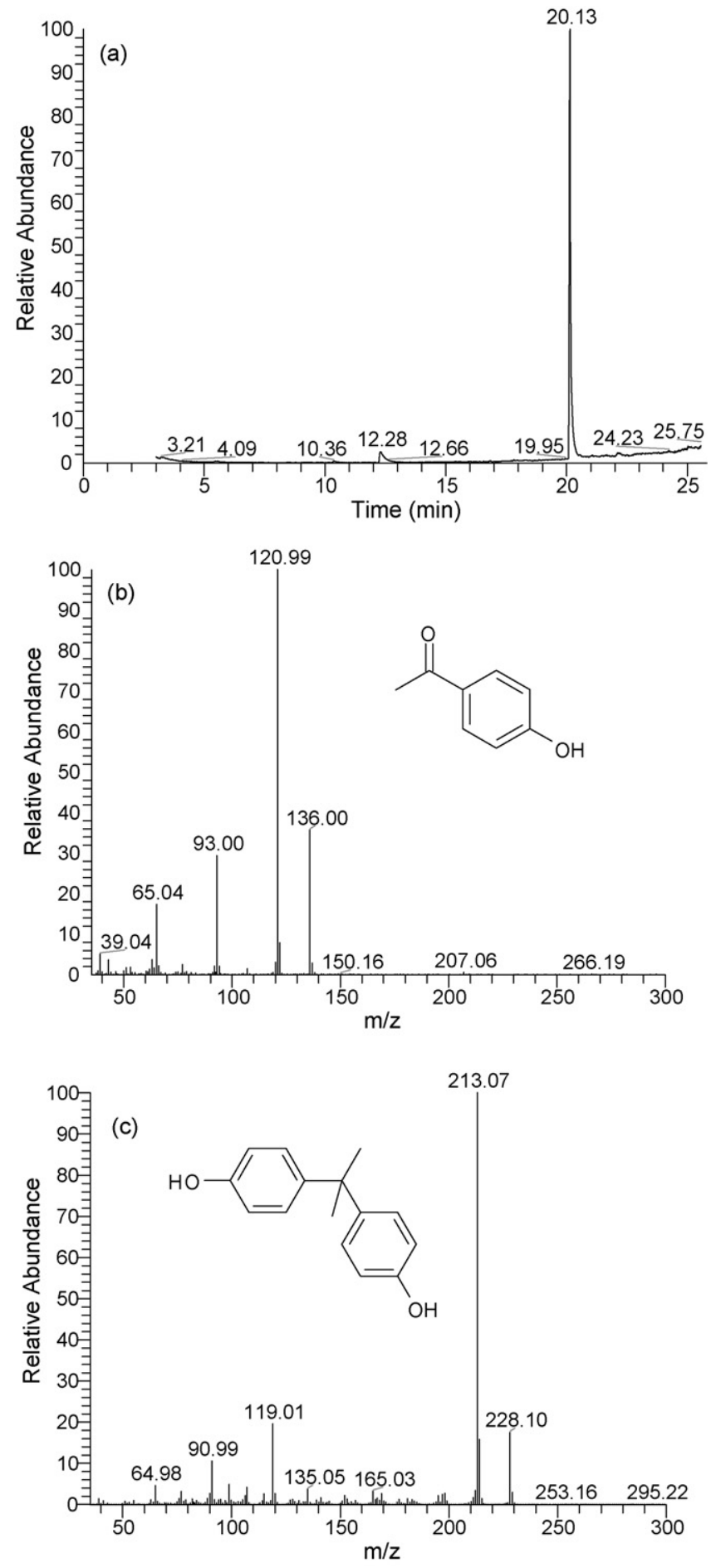

Fig. 4. (a) Chromatograph of BPA and one of its intermediates, 4-hydroxyacetophenone, by GC-MS. The retention time of BPA was 20.13 min, and that of 4-hydroxy-acetophenone was $12.28 \mathrm{~min}$. (b) Spectrum of 4-hydroxy-acetophenone. The molecular structure is also shown. (c) Spectrum of BPA. The molecular structure is also shown.

was different with that of CASR [28]. Thus, the BPA removal in MBR was faster than in CASR. Nevertheless, as time passed without discharge of sludge, the microorganisms in CASR could also remove BPA effectively, probably because of the increase of the BPA-degradable bacteria. Thus, the efficiencies of BPA removal in MBR and CASR tended to be same over longer periods.

Finally, because of the hydrophobicity of BPA, the adsorption of BPA into suspended solid and organic matter [29] should also be considered [30]. In this case, the rejection of the membrane might provide a safer method for decreasing the risk of released EDCs with effluent. There should be more investigations into this area.

\section{Conclusions}

The presented results concluded that the MBR could remove BPA slightly more effectively than CASR under conditions of equal sludge loadings ranging from 0.046 to $10.2 \mathrm{~g} \mathrm{~kg}^{-1} \mathrm{~d}^{-1}$. However, MBR could bear much higher volume loadings than CASR and still achieve the same BPA removal efficiencies. In MBR, HRT did not obviously influence the removal of BPA. Although BPA is hydrophobic, the contribution of sludge adsorption to removal was quite low, and biodegradation dominated the BPA removal process. The BPA biodegradation by sludge in MBR was supported by the detection of one metabolite, 4-hydroxy-acetophenone.

\section{Acknowledgement}

This work was supported by the Major International Joint Research Program of Natural Science Foundation of China (NSFC) (20721140019).

\section{References}

[1] Liang S. Bisphenol A, 1st ed., Beijing: Chemical Industry Press; 1981. p. 45-50 [in Chinese].

[2] Staples CA, Dorn PB, Klecka GM, O'Block ST, Harris LR. A review of the environmental fate, effects, and exposures of bisphenol A. Chemosphere 1998;36(10):2149-73.

[3] Yamamoto T, Yasuhara A, Shiraishi H, Nakasugi O. Bisphenol A in hazardous waste landfill leachates. Chemosphere 2001;42(4):415-8.

[4] $\mathrm{Du} \mathrm{B}$. The fate and modeling of environmental disrupting chemicals (EDCs) in a typical sewage treatment plant. Beijing: Dissertation submitted to Tsinghua University for the master's degree; 2003 [in Chinese].

[5] Lee HB, Peart TE. Bisphenol A contamination in Canadian municipal and industrial wastewater and sludge samples. Water Qual Res J Can 2000;35(2):283-98.

[6] Meesters RJW, Schroder HF. Simultaneous determination of 4-nonylphenol and bisphenol A in sewage sludge. Anal Chem 2002;74(14):3566-74.

[7] Shen G, Yu G, Cai ZX, Zhang ZL. Development of an analytical method to determine phenolic endocrine disrupting chemicals in sewage and sludge by GUMS. Chin Sci Bull 2005;50(23):2681-7.

[8] vom Saal FS, Nagel SC, Timms BG, Welshons WV. Implications for human health of the extensive bisphenol A literature showing adverse effects at low doses: a response to attempts to mislead the public. Toxicology 2005;212(2-3):244-52.

[9] Ashby J, Tinwell H, Odum J, Lefevre P. Natural variability and the influence of concurrent control values on the detection and interpretation of low-dose or weak endocrine toxicities. Environ Health Persp 2004;112(8):847-53.

[10] Nishizawa H, Morita M, Sugimoto M, Imanishi S, Manabe N. Effects of in utero exposure to bisphenol A on mRNA expression of arylhydrocarbon and retinoid receptors in murine embryos. J Reprod Dev 2005;51(3):315-24.

[11] Yoon YM, Westerhoff P, Snyder SA, Esparza M. HPLC-fluorescence detection and adsorption of bisphenol A, 17 beta-estradiol, and 17 alpha- 
ethynyl estradiol on powdered activated carbon. Water Res 2003;37(14):3530-7.

[12] Kitaoka M, Hayashi K. Adsorption of bisphenol A by cross-linked beta-cyclodextrin polymer. J Incl Phenom Macro 2002;44(1-4): 429-31.

[13] Aoki N, Nishikawa M, Hattori K. Synthesis of chitosan derivatives bearing cyclodextrin and adsorption of $p$-nonylphenol and bisphenol A. Carbohyd Polym 2003;52(3):219-23.

[14] Ohko Y, Ando I, Niwa C, Tatsuma T, Yamamura T, Nakashima T, et al. Degradation of bisphenol A in water by $\mathrm{TiO}_{2}$ photocatalyst. Environ Sci Technol 2001;35(11):2365-8.

[15] Thiruvenkatachari R, Kwon TO, Moon IS. Application of slurry type photocatalytic oxidation-submerged hollow fiber microfiltration hybrid system for the degradation of bisphenol A (BPA). Sep Sci Technol 2005;40(14):2871-88.

[16] Kuramitz H, Nakata Y, Kawasaki M, Tanaka S. Electrochemical oxidation of bisphenol A. Application to the removal of bisphenol A using a carbon fiber electrode. Chemosphere 2001;45(1):37-43.

[17] Sajiki J, Yonekubo J. Inhibition of seawater on bisphenol A (BPA) degradation by Fenton reagents. Environ Int 2004;30(2):145-50.

[18] Lobos JH, Leib TK, Su T-M. Biodegradation of bisphenol A and other bisphenols by a gram-negative aerobic bacterium. Appl Environ Microbiol 1992;58(6):1823-31.

[19] Kang JH, Kondo F. Bisphenol A degradation by bacteria isolated from river water. Arch Environ Contam Toxicol 2002;43(3):265-9.

[20] Spivack J, Leib TK, Lobos JH. Novel pathway for bacterial metabolism of bisphenol A-rearrangements and stilbene cleavage in bisphenol A metabolism. J Biol Chem 1994;269(10):7323-9.

[21] Wintgens T, Gallenkemper M, Melin T. Endocrine disrupter removal from wastewater using membrane bioreactor and nanofiltration technology. Desalination 2002;146(1-3):387-91.
[22] Wintgens T, Gallenkemper M, Melin T. Occurrence and removal of endocrine disrupters in landfill leachate treatment plants. Water Sci Technol 2003;48(3):127-34.

[23] Clara M, Strenn B, Ausserleitner M, Kreuzinger N. Comparison of the behaviour of selected micropollutants in a membrane bioreactor and a conventional wastewater treatment plant. Water Sci Technol 2004;50(5):2936.

[24] Clara M, Strenn B, Saracevic E, Kreuzinger N. Adsorption of bisphenolA, 17 beta-estradiole and 17 alpha-ethinylestradiole to sewage sludge. Chemosphere 2004;56(9):843-51.

[25] Clara M, Kreuzinger N, Strenn B, Gans O, Kroiss H. The solids retention time - a suitable design parameter to evaluate the capacity of wastewater treatment plants to remove micropollutants. Water Res 2005;39(1):97106.

[26] Urase T, Kikuta T. Separate estimation of adsorption and degradation of pharmaceutical substances and estrogens in the activated sludge process. Water Res 2005;39(7):1289-300.

[27] Kang JH, Katayama Y, Kondo F. Biodegradation or metabolism of bisphenol A: from microorganisms to mammals. Toxicology 2006;217(2-3):81-90.

[28] Luxmy BS, Nakajima F, Yamamoto K. Analysis of bacterial community in membrane-separation bioreactors by fluorescent in situ hybridization (FISH) and denaturing gradient gel electrophoresis (DGGE) techniques. Water Sci Technol 2000;41(10-11):259-68.

[29] Shon HK, Vigneswaran S, Snyder SA. Effluent organic matter (EfOM) in wastewater: constituents, effects, and treatment. Crit Rev Environ Sci Technol 2006;36(4):327-74.

[30] Yamamoto H, Liljestrand HM, Shimizu Y, Morita M. Effects of physicalchemical characteristics on the sorption of selected endocrine disruptors by dissolved organic matter surrogates. Environ Sci Technol 2003;37(12): 2646-57. 